\title{
Fan Flutter Computations Using the Harmonic Balance Method
}

Milind A. Bakhle

Glenn Research Center, Cleveland, Ohio

Jeffrey P. Thomas

Duke University, Durham, North Carolina

T.S.R. Reddy

University of Toledo, Toledo, Ohio 


\section{NASA STI Program . . . in Profile}

Since its founding, NASA has been dedicated to the advancement of aeronautics and space science. The NASA Scientific and Technical Information (STI) program plays a key part in helping NASA maintain this important role.

The NASA STI Program operates under the auspices of the Agency Chief Information Officer. It collects, organizes, provides for archiving, and disseminates NASA's STI. The NASA STI program provides access to the NASA Aeronautics and Space Database and its public interface, the NASA Technical Reports Server, thus providing one of the largest collections of aeronautical and space science STI in the world. Results are published in both non-NASA channels and by NASA in the NASA STI Report Series, which includes the following report types:

- TECHNICAL PUBLICATION. Reports of completed research or a major significant phase of research that present the results of NASA programs and include extensive data or theoretical analysis. Includes compilations of significant scientific and technical data and information deemed to be of continuing reference value. NASA counterpart of peer-reviewed formal professional papers but has less stringent limitations on manuscript length and extent of graphic presentations.

- TECHNICAL MEMORANDUM. Scientific and technical findings that are preliminary or of specialized interest, e.g., quick release reports, working papers, and bibliographies that contain minimal annotation. Does not contain extensive analysis.

- CONTRACTOR REPORT. Scientific and technical findings by NASA-sponsored contractors and grantees.

- CONFERENCE PUBLICATION. Collected papers from scientific and technical conferences, symposia, seminars, or other meetings sponsored or cosponsored by NASA.

- SPECIAL PUBLICATION. Scientific, technical, or historical information from NASA programs, projects, and missions, often concerned with subjects having substantial public interest.

- TECHNICAL TRANSLATION. Englishlanguage translations of foreign scientific and technical material pertinent to NASA's mission.

Specialized services also include creating custom thesauri, building customized databases, organizing and publishing research results.

For more information about the NASA STI program, see the following:

- Access the NASA STI program home page at http://www.sti.nasa.gov

- E-mail your question via the Internet to help@ sti.nasa.gov

- Fax your question to the NASA STI Help Desk at 301-621-0134

- Telephone the NASA STI Help Desk at 301-621-0390

- Write to: NASA Center for AeroSpace Information (CASI) 7115 Standard Drive Hanover, MD 21076-1320 


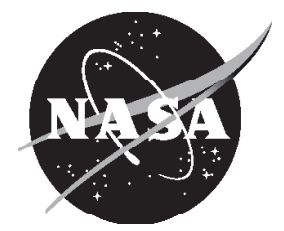

\section{Fan Flutter Computations Using the Harmonic Balance Method}

Milind A. Bakhle

Glenn Research Center, Cleveland, Ohio

Jeffrey P. Thomas

Duke University, Durham, North Carolina

T.S.R. Reddy

University of Toledo, Toledo, Ohio

Prepared for the

44th Joint Propulsion Conference and Exhibit

cosponsored by AIAA, ASME, SAE, and ASEE

Hartford, Connecticut, July 21-23, 2008

National Aeronautics and

Space Administration

Glenn Research Center

Cleveland, Ohio 44135 


\section{Acknowledgments}

Support for this work, from the NASA Fundamental Aeronautics Program, Subsonic Fixed Wing Project and Supersonics Project, is greatfully acknowledged.

This work was sponsored by the Fundamental Aeronautics Program at the NASA Glenn Research Center.

Level of Review: This material has been technically reviewed by technical management.

Available from

NASA Center for Aerospace Information 7115 Standard Drive

Hanover, MD 21076-1320
National Technical Information Service 5285 Port Royal Road Springfield, VA 22161

Available electronically at http://gltrs.grc.nasa.gov 


\title{
Fan Flutter Computations Using the Harmonic Balance Method
}

\author{
Milind A. Bakhle \\ National Aeronautics and Space Administration \\ Glenn Research Center \\ Cleveland, Ohio 44135 \\ Jeffrey P. Thomas \\ Duke University \\ Durham, North Carolina 27708 \\ T. S. R. Reddy \\ University of Toledo \\ Toledo, Ohio 43606
}

\begin{abstract}
An experimental forward-swept fan encountered flutter at part-speed conditions during wind tunnel testing. A new propulsion aeroelasticity code, based on a computational fluid dynamics (CFD) approach, was used to model the aeroelastic behavior of this fan. This three-dimensional code models the unsteady flowfield due to blade vibrations using a harmonic balance method to solve the Navier-Stokes equations. This paper describes the flutter calculations and compares the results to experimental measurements and previous results from a time-accurate propulsion aeroelasticity code.
\end{abstract}

\section{Introduction}

Research has been on-going in the development, validation and application of high-fidelity models for aeroelastic vibrations in aircraft engine fan, compressor, and turbine blades. Recent work has included time-domain solution of the Reynolds-averaged Navier-Stokes (RANS) equations to provide the unsteady flowfield and unsteady aerodynamic forces on the blades. An example of such work is the TURBO aeroelastic analysis code (refs. 1 and 2). Such high-fidelity time-domain models require large numbers of computations and take a long time for startup transients to decay before the final periodic solution is obtained. An alternate approach (ref. 3) is to use the periodicity in time of typical turbomachinery flows to represent each flow variable by a Fourier series in time, leading to a harmonic balance form of the Navier-Stokes equations. Solutions to these equations can be obtained using methods that are typically used for steady flow problems such as pseudo-time marching and local time stepping. Thus, the harmonic balance approach leads to a method that is significantly faster than the typical timedomain solution method (ref. 3).

In the present study, the harmonic balance aeroelastic analysis method and computer code developed by Hall et al. (refs. 3 and 4) is applied to the problem of part-speed fan flutter. The configuration selected is an experimental fan for which wind-tunnel data is available, and for which aeroelastic computations have been previously performed using a time-domain RANS aeroelastic code (ref. 1). The design and testing of the advanced single-stage transonic fan has been described in detail in a recent report (ref. 5). This fan was designed with aggressive goals for performance and noise reduction. During rig testing in a high-speed wind tunnel, the fan performed well at design speed, and was successfully throttled to the stall line. However, flutter was encountered just above the operating line at part-speed conditions. The flutter mode was identified as the first bending mode of the airfoil, in a two nodal diameter forward-traveling wave pattern.

In the present work, a computational study was performed to examine the flutter characteristics using a new state-of-the-art propulsion aeroelasticity code based on the harmonic balance method. This code (ref. 4) solves the three-dimensional unsteady, Reynolds-Averaged Navier-Stokes equations with the ability to model a rotating blade row with harmonic blade vibrations or incoming periodic distortions. For flutter calculations, the blade vibration is prescribed to be the modal deflection and a frequency, both of which are calculated from a separate structural dynamics analysis. Computations are performed in a single blade passage for both steady and unsteady analysis. The resulting unsteady pressures are used to calculate a generalized aerodynamic force and then an eigenvalue problem is solved to calculate the aerodynamic damping, which is used to determine stability of the blade in a specific 
vibration mode. Note that in the present study, the harmonic balance aeroelastic code was run with very small amplitude vibrations of the fan blade to calculate linearized unsteady aerodynamics for a conventional linear flutter analysis. Although the harmonic balance method provides a computationally efficient frequency-domain solution for modeling nonlinear unsteady aerodynamic effects due to finite amplitude blade vibrations motions, the present calculations have been restricted to small amplitude vibrations in order to examine only linearized aerodynamic characteristics.

\section{Analysis}

\section{A. Aeroelastic Model}

The equations of motion for a fan blade (with all blades assumed to be identical) can be written as

$$
[M]\{\ddot{q}\}+[K]\{q\}=[A]\{q\}
$$

where $[M]$ and $[K]$ are generalized mass and stiffness matrices, $\{q\}$ is the generalized displacement vector, and $[A]$ is the blade vibration-dependent generalized aerodynamic force matrix. The matrices $[M],[K]$ and $[A]$ are of size $N M \times N M ;\{q\}$ is of size $N M \times 1 ; N M$ is the number of modes.

The elements of $[M]$ and $[K]$ are obtained from a free-vibration analysis using a commercial structural dynamics analysis software. The matrices $[M]$ and $[K]$ are diagonal and their non-zero elements are related as

$$
K_{i}=M_{i} \omega_{i}^{2}(1+2 i \zeta)
$$

where $\omega_{i}$ is the natural frequency of the $i^{\text {th }}$ mode, and $\zeta$ is the structural damping ratio; usually the mode shapes are mass-normalized and therefore $M_{i}=1$.

Since all the blades are identical (that is, a tuned rotor), the aeroelastic modes consist of individual blades vibrating with equal amplitudes at a fixed interblade phase angle between adjacent blades. Hence, the motion of the $s^{\text {th }}$ blade in $r^{\text {th }}$ interblade phase angle mode can be written as

$$
\left\{q_{s}\right\}=\left\{q_{r}\right\} e^{i \omega t} e^{i \sigma_{r} s}
$$

where $\omega$ is the vibration frequency, $\sigma_{r}$ is the interblade phase angle related to nodal diameter $(N D)$ pattern of the traveling wave and number of blades $N_{\text {blades }}$ as

$$
\sigma_{r}=2 \pi N D / N_{\text {blades }}
$$

Thus, the equations of motion for a blade become

$$
-\omega^{2}[M]\left\{q_{r}\right\}+[K]\left\{q_{r}\right\}=\left[A_{r}\right]\left\{q_{r}\right\}
$$

\section{B. Calculation of Aerodynamic Force Matrix $\left[A_{r}\right]$}

Flutter analysis requires the calculation of all elements of the generalized aerodynamic force matrix $\left[A_{r}\right]$. Unsteady flowfield computations are carried out for each vibration mode and assumed frequency. For a selected value of interblade phase angle, the harmonic balance code is used to calculate the unsteady pressure distribution on the blade surface, which is further used to calculate the (complex-valued) elements of the generalized aerodynamic force matrix $\left[A_{r}\right]$. This calculation is repeated for $N_{\text {blades }}$ interblade phase angles given by eq. (4).

\section{Flutter Analysis}

An eigenvalue approach is used to determine flutter stability. Equation (5) is written in a standard eigenvalue form as: 


$$
[[P]-\gamma[Q]]\left\{q_{r}\right\}=\{0\}
$$

where $[P]=\left([K]-\left[A_{r}\right]\right) / \omega_{o}^{2} ;[Q]=[M] ; \gamma=\left(\omega / \omega_{o}\right)^{2}$; and $\omega_{o}$ is the assumed frequency used in the calculation of the elements of the aerodynamic force matrix $\left[A_{r}\right]$.

The solution of the above eigenvalue problem results in $N M$ complex eigenvalues of the form

$$
i\left(\omega / \omega_{o}\right)=i \sqrt{\gamma}=\bar{\mu} \pm i \bar{\nu}
$$

The real part of the eigenvalue $(\bar{\mu})$ represents the damping ratio, and the imaginary part $(\bar{v})$ represents the damped frequency; flutter occurs if $\bar{\mu} \geq 0$ for any eigenvalue.

For turbomachinery blades, flutter analysis is usually carried out with a single vibration mode. In this case, eq. (6) reduces to a scalar equation and the eigenvalues can be written as

$$
\gamma=P / Q
$$

In the present work, the structural damping is set to zero and the vibration mode is mass-normalized, leading to the following simplified solution for the eigenvalue problem

$$
\gamma=\left(\omega_{\text {natural }}^{2}-A\right) / \omega_{o}^{2}
$$

Note that the frequency used in the unsteady aerodynamic calculations $\left(\omega_{o}\right)$ has the same value as the blade natural frequency $\left(\omega_{\text {natural }}\right)$. Also note that since the structural damping is set to zero, the damping is referred to as aerodynamic damping in the following section, but it is opposite in sign to $\bar{\mu}$.

\section{Results}

In this section, the results of the steady and unsteady computations are presented. Steady and unsteady computations were carried out using the TURBO code at rotational speeds of 85 and 75 percent. These two speeds were selected since during testing, large vibratory responses due to flutter were encountered on the stall side of the operating line at these speeds. Note that during testing at 100 percent (design) speed, no flutter was encountered.

Note that in the present work, the harmonic balance aeroelastic code was run with very small amplitude vibrations of the fan blade to calculate linearized unsteady aerodynamics for a conventional linear flutter analysis.

\section{A. Steady Computational Results}

In this study, the airfoil geometry used was calculated based on static deflections obtained from structural analysis for 85 percent speed. The static deflections included the effects of rotational speed, applied pressures, and blade temperatures; nonlinear geometry effects were also included in the analyses. The blade geometry at 85 percent speed and nominal operating conditions was used for all computations. Previous calculations (ref. 1) for this case have shown that changes from the nominal blade geometry due to changes in rotational speed were not significant and therefore a single geometry was used for computations at all speeds and operating conditions in the present work. The computational grid used was generated using commercial software. The grid is shown in figure 1; the grid size is $193 \times 33 \times 49$ for the block that wraps around the blade airfoil with 193 grid points around the airfoil, 33 grid points in the circumferential direction, and 49 grid points in the spanwise direction. The grid blocks in the inlet and exit sections are each $17 \times 33 \times 49$ with 17 points in the streamwise direction, 33 grid points in the circumferential direction, and 49 grid points in the spanwise direction. The tip clearance was based on rig test measurements and is modeled using 9 points between the blade tip and casing. 

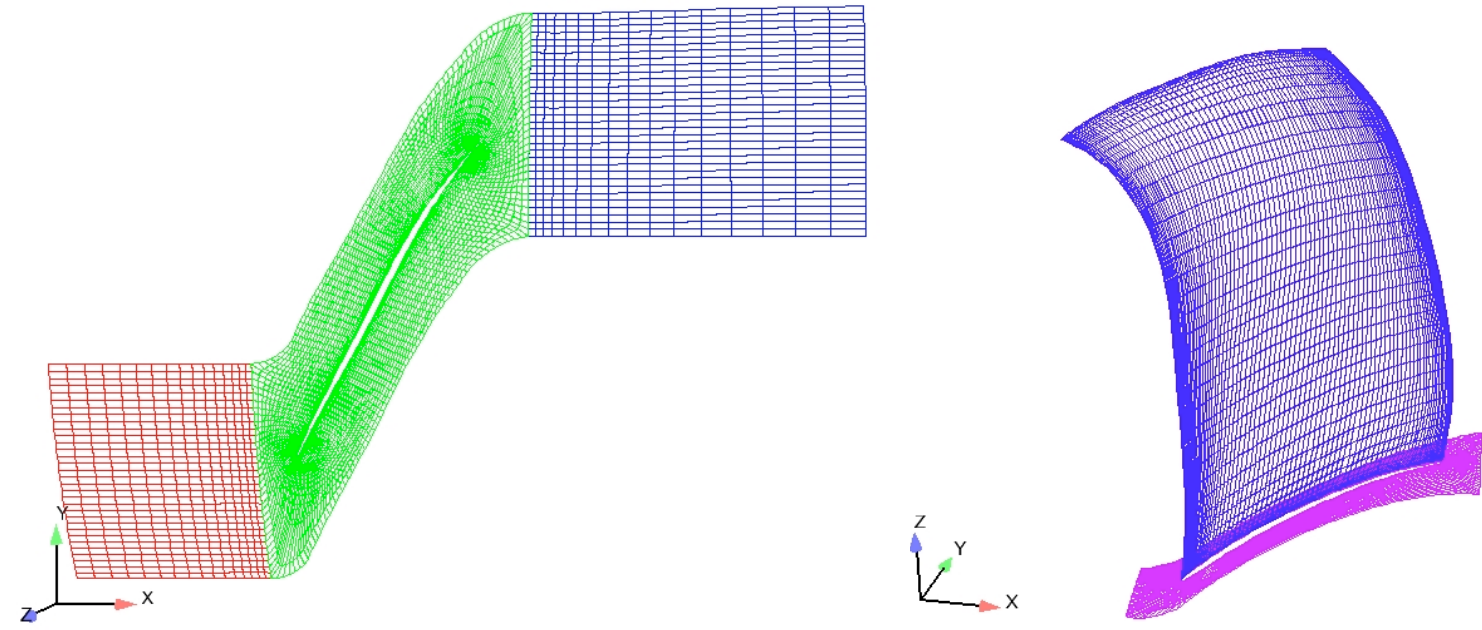

Figure 1.-Computational mesh.

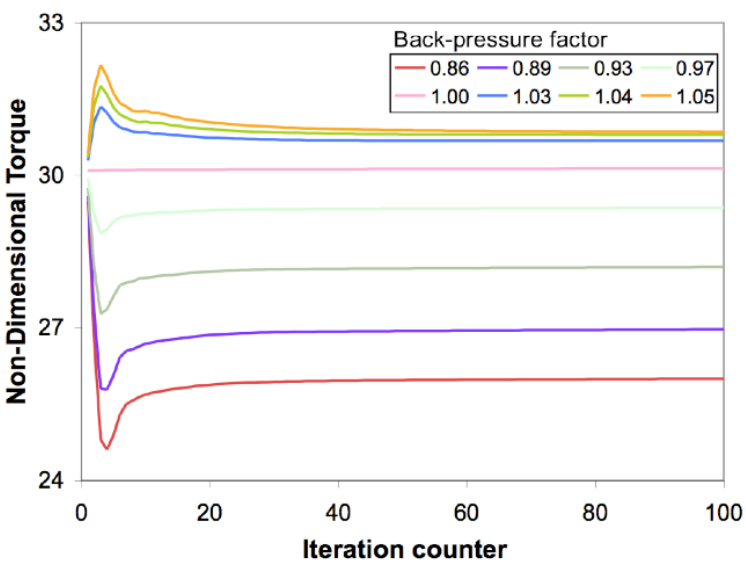

Figure 2.-Steady solution convergence.

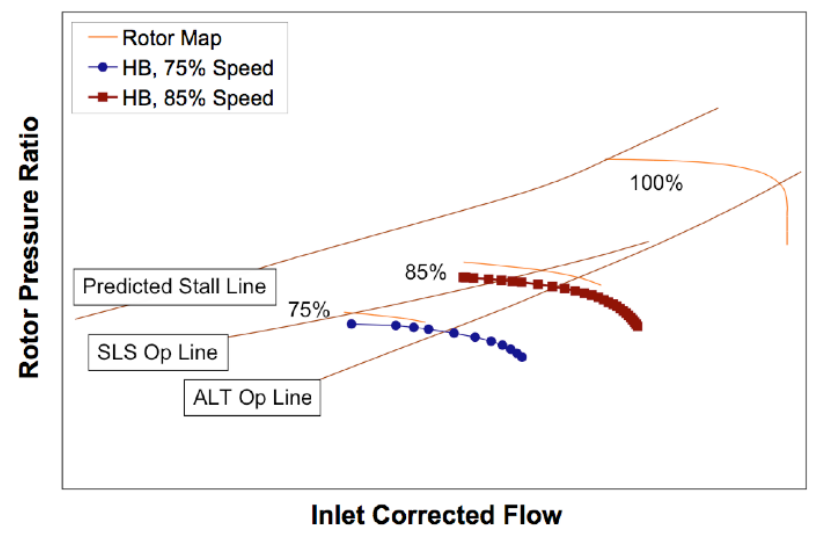

Figure 3.-Fan map showing current performance predictions.

The inlet flow conditions used in the computations consisted of circumferentially-averaged radial profiles of total pressure, total temperature, and flow angles. These prescribed profiles were based on rig measurements, supplemented by previous steady computations. The exit flow conditions consisted of a circumferentially-averaged radial profile of static pressure. This profile, which was based on pressure measurements at design speed, was used with uniform scaling for the computations at all speeds and at all conditions.

Figure 2 shows the convergence of the steady computations as a plot of non-dimensional torque with iteration counter (100 iterations per counter). The computations were carried out at 85 percent speed for various values of imposed back-pressure at the exit boundary. As can be noted from figure 2, excellent convergence was obtained for all operating conditions. Similar convergence was obtained for the computations at 75 percent speed. All steady results presented here are from well-converged solutions.

The experimental fan map is shown in figure 3 along with the results of current steady computations denoted as HB. Several computations were done for 85 and 75 percent speeds and the results correlate well with measurements. Of particular interest is the last condition computed on the stall side, beyond which no converged solutions were obtained. The mass flow rate at the near-stall point is in excellent agreement with measurements; the predicted pressure ratio is approximately 3 percent lower at both speeds. No converged solutions were obtained at 85 percent speed for lower mass flow rates beyond those shown in figure 3 . For 75 percent speed, additional calculations are required with small increases in back-pressure to determine if additional stable solutions can be obtained for lower mass flow rates. Note that the stall line shown in figure 3 was estimated based on prior experience and was not confirmed during rig testing because of the occurrence of flutter. Also, since the stall side was of primary interest, no attempt was made to determine the upper bound on choke flow. 


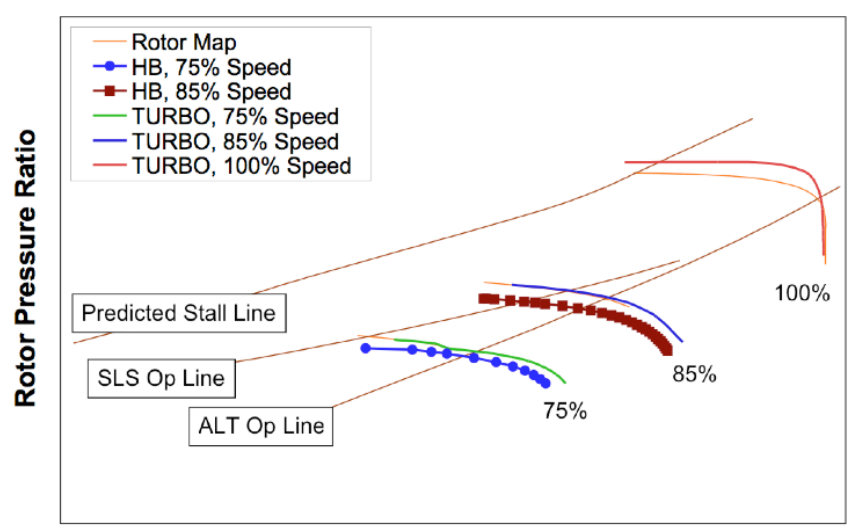

Inlet Corrected Flow

Figure 4.-Fan map showing current performance predictions compared with TURBO results (ref. 1).

Figure 4 shows a comparison of the present results for performance compared to the previous computational results from the TURBO code (ref. 1). The present results show good correlation with the TURBO results, except that both 75 and 85 percent speed lines are shifted towards lower mass flow rate and lower pressure ratio. The present calculations provide converged results for lower mass flow rates than were obtained with TURBO. Also, the present results consistently show a lower pressure ratio as compared to TURBO and the test data. These differences need to be investigated further. It should be noted that significant differences exist between the numerical method used in the previous TURBO computations and the current computations with the harmonic balance code. These differences include time-domain versus frequency-domain, numerical discretization, grid, and algorithm used to solve the RANS equations, turbulence modeling, and others. Therefore, the differences in results noted in figure 3 are not entirely surprising. Also, additional sensitivity studies are required to determine the variability in the newly computed results.

\section{B. Unsteady Computational Results}

Unsteady computations were performed using the harmonic balance code at 85 and 75 percent speeds to predict the aeroelastic stability of the blade. Several nodal diameters covering the entire possible range were considered. The steady condition near peak-efficiency was used along with a condition near the stall line. This allowed the trend along the speed line to be assessed. Note that the results presented in this paper were all computed with only the $0^{\text {th }}$ and $1^{\text {st }}$ harmonics included in the aerodynamic analysis using the harmonic balance method.

Figure 5 shows the convergence of the unsteady computations as a plot of non-dimensional generalized force (real and imaginary parts) with iteration counter (100 iterations per counter) for various nodal diameters. These computations were for 85 percent speed and for an operating point near the peak-efficiency condition with a nondimensional back-pressure of 1.0. As can be noted, although the rates of convergence vary with nodal diameter, all the results are well-converged. Similar convergence characteristics were observed at the near-stall condition with a non-dimensional back-pressure of 1.05 .

A sensitivity study was performed to investigate the effect of the unsteady grid scaling parameter. The nominal value of this numerical input parameter was increased by factors of 2 and 5, and then decreased by the same factors. There was no change in the generalized force results within plotting accuracy-demonstrating that for the present calculations, the prescribed unsteady grid scaling has no effect on the results. Recall that in the present study, the harmonic balance aeroelastic code was run with very small amplitude vibrations of the fan blade to calculate linearized unsteady aerodynamics for a conventional linear flutter analysis.

Figure 6 shows the variation of the converged generalized force with nodal diameter for the two different values of back-pressure at 85 percent speed. Note the significant variation in the imaginary part of the generalized force. For a single vibration mode, the stability is determined by the imaginary part of the generalized force and figure 6 shows that the stability varies significantly with nodal diameter. Further, with the change in back-pressure from peak-efficiency towards stall, it can be seen that the imaginary part of the generalized force drops closer to zero at 
$N D=2$. This trend is seen more clearly in figure 7. The imaginary part of the generalized force is seen to clearly move towards zero as the back-pressure increases-going from peak-efficiency towards stall. Note that figure 7 includes results at non-dimensional back-pressure values of 1.052 and 1.0522 , with a change in the sign of the imaginary part occurring between these conditions.

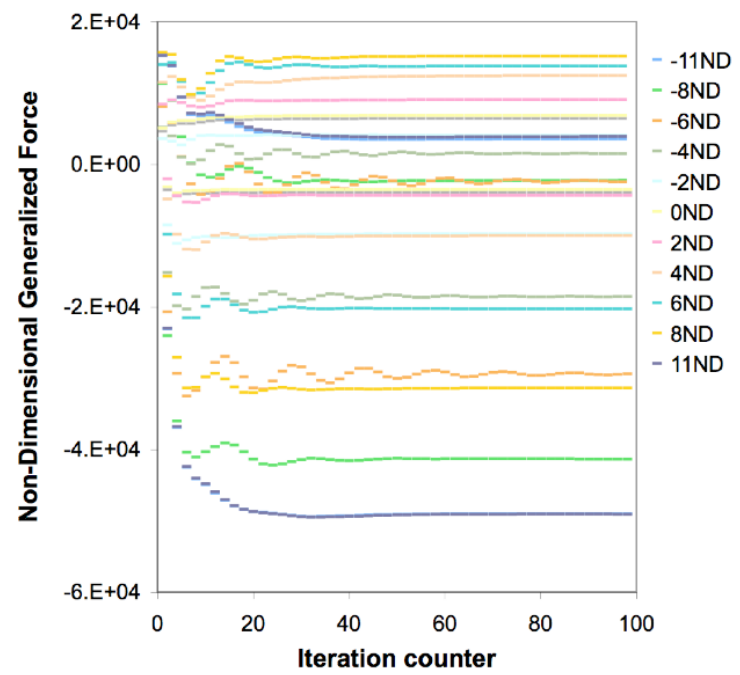

Figure 5.-Unsteady solution convergence.

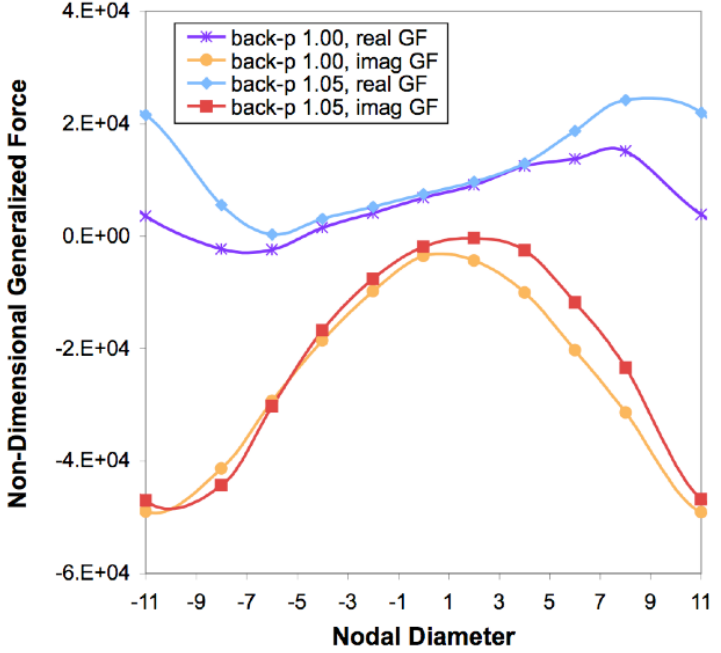

Figure 6.-Generalized force variation with nodal diameter.

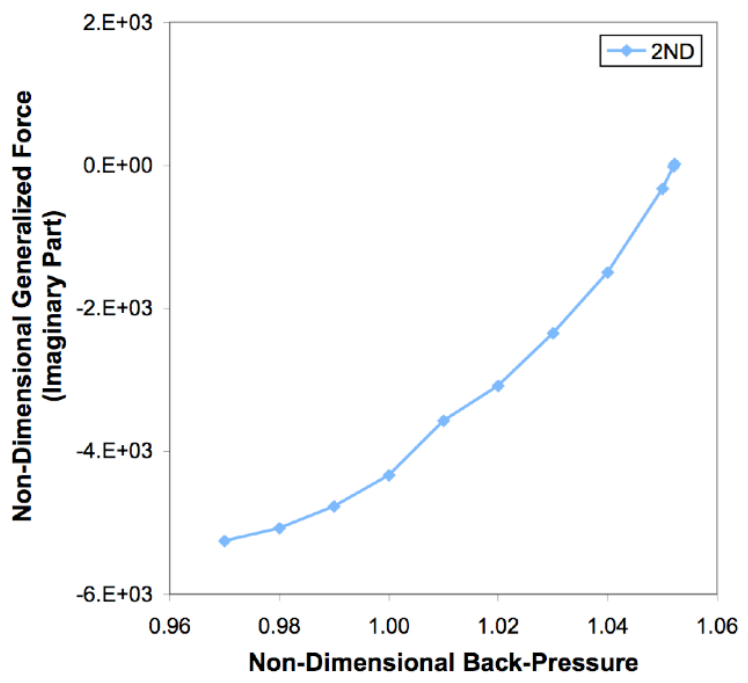

Figure 7.-Variation of generalized force (imaginary part) with back-pressure for $N D=2$. 


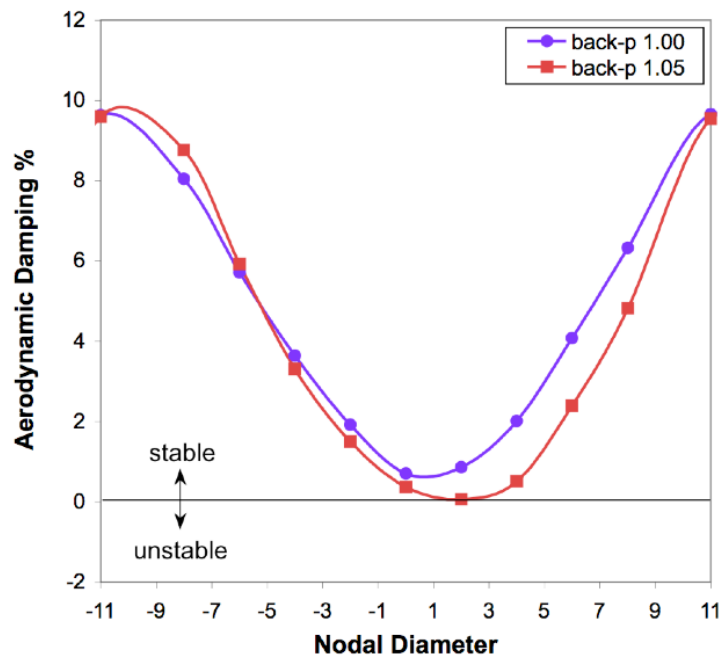

Figure 8.- Variation of aerodynamic damping with nodal diameter at 85 percent speed.

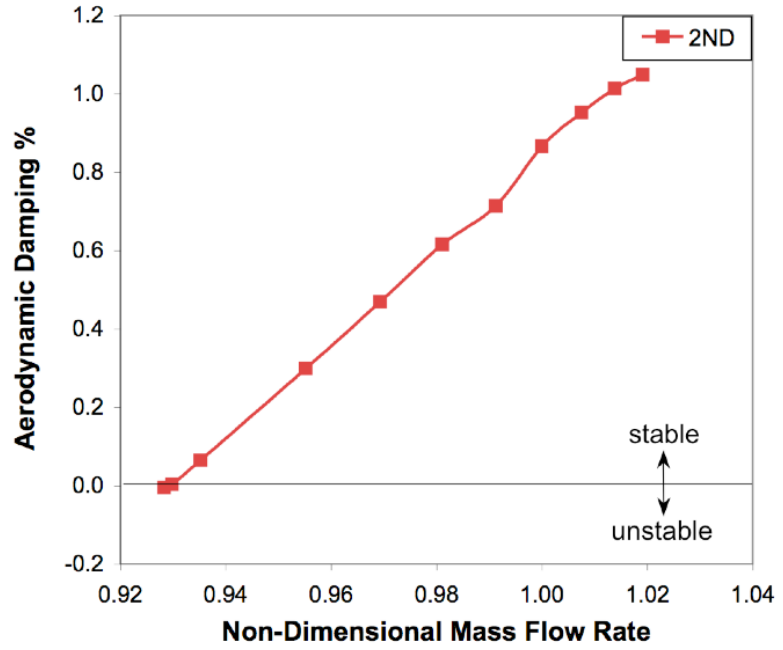

Figure 9.-Variation of aerodynamic damping with non-dimensional mass flow rate for $N D=2$ at 85 percent speed.

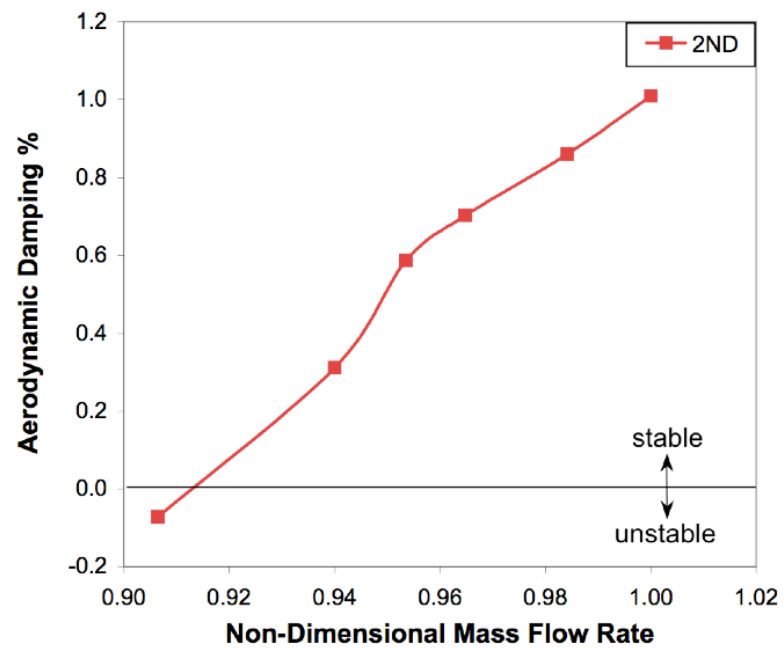

Figure 10.-Variation of aerodynamic damping with non-dimensional mass flow rate for $N D=2$ at 75 percent speed.

The generalized force was used to calculate the aerodynamic damping, which is plotted in figure 8. The results are presented for back-pressure values near peak-efficiency and near-stall conditions. The aerodynamic damping is seen to vary by an order of magnitude with nodal diameter of the traveling wave, with the minimum occurring at $N D=2$ (forward traveling wave). Note that although the damping value is nearly zero at the NS condition, it is still positive even at its minimum value, indicating stability at a non-dimensional back-pressure of 1.05.

Additional calculations were carried out for a small increase in back-pressure to identify the condition of zero aerodynamic damping (flutter). In the absence of these additional results at back-pressure of 1.052 and 1.0522, it would be necessary to extrapolate the damping as a function of mass flow to identify the flutter point. Figure 9 shows the variation of aerodynamic damping with mass flow rate with a clear monotonic drop in stability along the speed line towards stall. The results of unsteady calculations at 75 percent speed show trends that are nearly the same as those in figures 5 to 9 . Figure 10 shows the corresponding variation of aerodynamic damping along the 75 percent speed line. Note that the aerodynamic damping is clearly negative at the lowest mass flow rate condition and the flutter point is obtained by interpolation. 


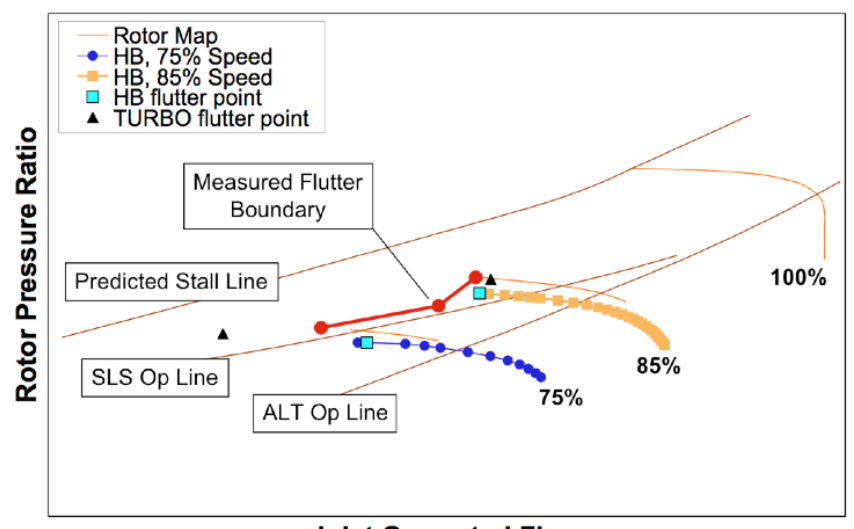

Inlet Corrected Flow

Figure 11.-Fan map showing calculated flutter point along with the measured flutter boundary.

The calculated flutter points at 85 and 75 percent speeds are plotted on the fan map along with the measured flutter boundary in figure 11. It can be seen that the calculated flutter point is very close to the measured value at 85 percent sped with a difference of less than 0.5 percent in mass flow rate. As noted previously, the pressure ratio is under-predicted and the difference from the measured data is 3 percent at the flutter point. For comparison, the flutter point calculated using TURBO is also plotted. Both calculations are very close to the test data; the present calculated result is slightly closer to the measurement in mass flow rate, but farther in pressure ratio as compared to the TURBO result.

At 75 percent speed, the difference between the present results and measurements is higher (about 4 percent) than at 85 percent speed. The TURBO result also shows a larger difference from measurement at 75 percent speed than at 85 percent speed.

\section{Conclusion}

Steady and unsteady computations have been carried out using a Propulsion Aeroelasticity code based on the harmonic balance method of solving the Reynolds-Averaged Navier-Stokes equations. The configuration selected was an experimental fan that encountered flutter during wind tunnel testing. The computational results were summarized and compared with experimental data and results from a previous computational study with a timedomain propulsion aeroelasticity code (TURBO). Overall, the results are in good agreement with experimental data and the previous TURBO results. The steady results were compared on the performance map and showed good correlation with data and TURBO results. However, the present results under-predict the pressure ratio. Also, the present analysis provides solutions at slightly lower mass flow rates than were obtained with TURBO. The systematic under-prediction of the pressure ratio by about 3 percent needs to be investigated further. A detailed look at the flowfield will provide additional information regarding the source of the lower pressure ratio. Also, numerical studies are required to investigate the sensitivity of the present results to numerical input parameters.

The flutter results correlated very well with the experimental data and the previous results from TURBO. The least stable nodal diameter pattern (interblade phase angle) matched correctly with the experimental observations and TURBO results. The calculated flutter condition agreed closely with the experimental data and TURBO results. A sensitivity study on the grid motion scaling parameter showed that the present results were insensitive to variations in the selected value of this parameter, thus demonstrating the linearity of the results for the selected small amplitude of blade vibration.

In the present work, computations were restricted to the first bending mode of vibration. Computations with other modes are required to show that the first mode is the least stable mode. Additional steady and unsteady computations are required to determine at 100 percent speed to demonstrate that no flutter is predicted for 100 percent speed, consistent with experimental observations and previous calculations with TURBO.

The real power of the harmonic balance method is that it can be a computationally efficient frequency-domain alternative to more computationally expensive time-domain methods for modeling nonlinear unsteady aerodynamic effects brought about by finite-amplitude blade vibrations. However, the present nonlinear harmonic balance 
aeroelastic code also provides capabilities for a linearized analysis as a special case. In the present study, very small amplitude vibrations were prescribed to calculate linearized unsteady aerodynamics for a conventional linear flutter analysis as a first step to understand the characteristics of the harmonic balance code and of the flutter of an experimental fan. Future work will investigate the non-linear amplitude-dependent effects using the same harmonic balance aeroelastic code.

\section{References}

1. Bakhle, M.A., Srivastava, R., Panovsky, J., Keith, T.G., Jr., Stefko, G.L., "Flutter Calculations of an Experimental Fan," Paper US-2, CEAS/AIAA/NVvL International Forum on Aeroelasticity and Structural Dynamics, Amsterdam, June 4-6 2003.

2. Srivastava, R., Bakhle, M.A., and Keith, T.G., Jr., "Numerical Simulation of Aerodynamic Damping for Flutter Analysis of Turbomachinery Blade Rows," Journal of Propulsion and Power, vol. 19, no. 2, MarchApril 2003.

3. Hall, K.C., Thomas, J.P., and Clark, W.S., "Computation of Unsteady Nonlinear Flows in Cascades Using a Harmonic Balance Technique," AIAA Journal, vol. 40, no. 5, May 2002.

4. Ekici, K., Hall, K.C., "Nonlinear Analysis of Unsteady Flows in Multistage Turbomachines Using Harmonic Balance," AIAA Journal, vol. 45, no. 5, May 2007, pp. 1047-1057.

5. Weir, D., "NASA AST-AOI 14, Design and Test of Fan and Nacelle Models for Quiet High Speed Fan—Final Report,"NASA/CR—2003-212370, July 2003. 


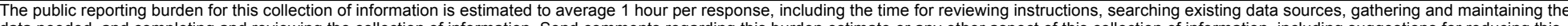

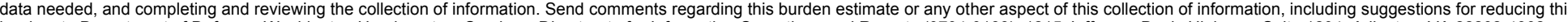

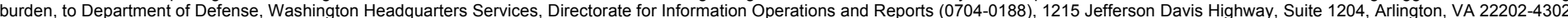

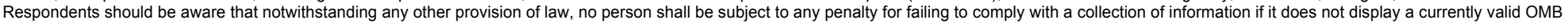
control number.

PLEASE DO NOT RETURN YOUR FORM TO THE ABOVE ADDRESS.
1. REPORT DATE (DD-MM-YYYY)
2. REPORT TYPE

\section{DATES COVERED (From - To)}

01-02-2009

Technical Memorandum

\section{TITLE AND SUBTITLE}

Fan Flutter Computations Using the Harmonic Balance Method

5a. CONTRACT NUMBER

5b. GRANT NUMBER

5c. PROGRAM ELEMENT NUMBER

\section{5d. PROJECT NUMBER}

6. AUTHOR(S)

Bakhle, Milind, A.; Thomas, Jeffrey, P.; Reddy, T., S., R.

5e. TASK NUMBER

5f. WORK UNIT NUMBER

WBS 561581.02.08.03.19.03; WBS

984754.02.07.03.16.05

7. PERFORMING ORGANIZATION NAME(S) AND ADDRESS(ES)

National Aeronautics and Space Administration

8. PERFORMING ORGANIZATION REPORT NUMBER

John H. Glenn Research Center at Lewis Field

E-16570

Cleveland, Ohio 44135-3191

\section{SPONSORING/MONITORING AGENCY NAME(S) AND ADDRESS(ES)}

National Aeronautics and Space Administration

Washington, DC 20546-0001

\section{SPONSORING/MONITORS ACRONYM(S) \\ NASA}

\section{SPONSORING/MONITORING} REPORT NUMBER

NASA/TM-2009-215301

\section{DISTRIBUTION/AVAILABILITY STATEMENT}

Unclassified-Unlimited

Subject Categories: 07 and 05

Available electronically at http://gltrs.grc.nasa.gov

This publication is available from the NASA Center for AeroSpace Information, 301-621-0390

\section{SUPPLEMENTARY NOTES}

\section{ABSTRACT}

An experimental forward-swept fan encountered flutter at part-speed conditions during wind tunnel testing. A new propulsion aeroelasticity code, based on a computational fluid dynamics (CFD) approach, was used to model the aeroelastic behavior of this fan. This threedimensional code models the unsteady flowfield due to blade vibrations using a harmonic balance method to solve the Navier-Stokes equations. This paper describes the flutter calculations and compares the results to experimental measurements and previous results from a time-accurate propulsion aeroelasticity code.

\section{SUBJECT TERMS}

Fan blade; Flutter; Navier-Stokes equation; Turbomachinery; Aeroelasticity

\begin{tabular}{|c|c|c|c|c|}
\hline \multicolumn{3}{|c|}{ 16. SECURITY CLASSIFICATION OF: } & \multirow{2}{*}{$\begin{array}{l}\text { 17. LIMITATION OF } \\
\text { ABSTRACT }\end{array}$} & \multirow{2}{*}{$\begin{array}{l}\text { 18. NUMBER } \\
\text { OF } \\
\text { PAGES } \\
15\end{array}$} \\
\hline $\begin{array}{l}\text { a. REPORT } \\
\text { U }\end{array}$ & $\begin{array}{l}\text { b. ABSTRACT } \\
U\end{array}$ & $\begin{array}{l}\text { c. THIS } \\
\text { PAGE } \\
\text { U }\end{array}$ & & \\
\hline
\end{tabular}

19a. NAME OF RESPONSIBLE PERSON
STI Help Desk (email:help@sti.nasa.gov)
19b. TELEPHONE NUMBER (include area code)
301-621-0390

Standard Form 298 (Rev. 8-98) Prescribed by ANSI Std. Z39-18 

